\title{
Valuation of Decision Flexibility and Strategic Value in Coal Gasification Projects with the Option-To-Switch between Different Outputs
}

\author{
Piotr W. Saługa ${ }^{1, *}$, Paweł Grzesiak ${ }^{2}$ and Jacek Kamiński ${ }^{3}$ \\ 1 Management Department, WSB University, 41-300 Dąbrowa Górnicza, Poland \\ 2 Faculty of Management, AGH University of Science \& Technology, 30-067 Kraków, Poland; \\ pawel.jan.grzesiak@zarz.agh.edu.pl \\ 3 Division of Energy Economics, Mineral and Energy Economy Research Institute of the Polish Academy of \\ Sciences, 31-261 Kraków, Poland; kaminski@min-pan.krakow.pl \\ * Correspondence: psaluga@wsb.edu.pl; Tel.: +48-724-028-746
}

Received: 15 April 2020; Accepted: 25 May 2020; Published: 2 June 2020

check for updates

\begin{abstract}
Coal gasification has been promoted as a sophisticated clean energy technology alternative to coal burning these days. Aside from the usual technical difficulties, economic issues of such projects-especially valuation challenges-are important problems that practitioners usually struggle with. This is because of the major extent of managerial flexibility linked with specific characteristics of coal gasification projects, in particular, possibilities to mothball/restart manufacturing lines, or change between different outputs. The value of such flexibilities may be well assessed by real options valuations. The aim of this paper is to show that for the coal gasification technologies the real options valuation is more suitable than traditional discounted cash flow technique. This approach was applied to calculate an integrated plant that can produce either electricity or methanol. As the valuation approach the multiplicative stochastic process was used. As a consequence, binomial lattices of end-product (electricity and methanol) were developed. Then, in regard to them (reference instruments), two corresponding lattices of net cash flows (consecutive instruments) were created. In the end, two trees of switching option value were developed-one for electricity production as an initial mode, and the second for methanol production, delivering expanded net present (strategic) value.
\end{abstract}

Keywords: coal gasification; compound options; option-to-switch; real options analysis; binomial lattice; strategic value

\section{Introduction}

One of the most significant indicators and economic criteria applied in liberalized energy sectors is the category of value. Valuations are being made in order to secure companies' and investors' rights and interests and to support investment decisions, management, and operating performance. The valuation of projects is an important issue, in particular in liberalized energy markets, where power generation companies are forced to compete [1]. Hence the risk of making wrong decisions is higher and the outcomes are intensified.

Due to the ongoing low carbon emission directives, in particular in Europe, one of the most risky sectors turns out to be the coal sector [2]. Not only coal mines, but also coal consumers (such as coal-based power companies) are particularly affected by carbon emission reduction regulations [3]. Several projects are currently either suspended or cancelled in Europe, and it seems this may continue in the long run. However, there are some technologies that could be considered attractive, even though 
the market position of coal is diminishing. One of the very few examples of such technologies is gasification.

The concept of coal gasification is based on a set of multidirectional thermal and chemical transformations that occur at increased temperatures mainly between the organic portion of the carbon matter and reactants such as carbon dioxide, oxygen, or water vapor. These changes result in the formation of flammable gas constituting fuel or chemical material [4]. Depending on the reactivity of the carbon, the production process or the type of reactor, a variety of media may be used in the process of gasification: usually air, air and water vapor, oxygen and water vapor, steam, hydrogen, or carbon dioxide.

The coal gasification process using a variety of gasification factors is carried out at high temperature $1200-1800{ }^{\circ} \mathrm{C}$ and a pressure of $2-7 \mathrm{MPa}$. The process can be carried out in surface installations or in underground georeactors. Further processes of purification and treatment of the gas allow heat recovery, relatively easy separation, and sequestration of $\mathrm{CO}_{2}$ and the obtaining of syngas and hydrogen, which can be further used in the chemical or energy industry [5].

The surface coal gasification process is conducted in specially designed reactors. The most commonly used processes, oxygen and steam gasification, allow water gas, average-caloric, or synthetic natural gas to be obtained [6]. Depending on the structure of fuel flow in the reaction zone of the process, reactor designs can be divided into reactors with a moving bed, fluidized bed, or entrained flow $[7,8]$.

The underground gasification process takes place in the seam, without the need to bring the coal up to the surface. The deposit is reached from the surface by a set of wells which are used to service the process. The oxidizing agent (air or oxygen) is injected into the seam and reacts with carbon. The process starts by setting light to the seam at the beginning of a passage connected to the vertical wells. The proper gasification process starts while the fire zone is being formed. At the same time, as the fire front moves, a cavern filled with ash and slag is created-and above it the caving zone is formed $[9,10]$.

A reliable valuation of such technologically complex projects is often a sophisticated, multi-staged challenge. A project's fundamental (or intrinsic) value is commonly derived from discounted cash flow analysis (DCF), whilst the market value is assessed through a comparable sales approach. Due to the fact that the latter process is not a truly analytical technique, the net present value (NPV) obtained from the DCF analysis is perceived as an expectation of market value when analysts are unbiased. Having the same expectations, one may anticipate that competition among market participants will cause the intrinsic value to reach the level of the market value.

In fact, NPV very rarely equals market value, which significantly reduces the reliability of results of the DCF analysis. This approach only assumes one scenario of possible events: the project will generate the expected cash flows according to the adopted financial and technical characteristics within the predicted lifetime. All project uncertainties are reflected in only one parameter-a discount rate. The calculations mean that higher discount factors (i.e., higher risks) indicate lower NPVs but the real confusion stems from the fact that in the case of long-term projects, high discount factors seem to underrate cash flow values arising in later years. That is why this technique is barely suitable for evaluating risky projects.

It goes without saying that risks create opportunities that are sources of some value. It is commonly known that DCF analysis does not take into consideration the value of flexibility related to the optimal timing of a project and/or (once it is operational) modifying operating strategies. The implementation of such opportunities (real options) may significantly limit downside losses (or increase upside gains) of shareholders. The value of managerial flexibility can be an important component of the strategic value of projects.

Apart from delaying a project, managers in the operational phase can modify decisions taken at the start-up of the project:

- increase or reduce the scale of the project, 
- temporarily shut down and re-open production,

- abandon the project.

Considering coal gasification projects, they are inherently risky and volatile and, therefore, have specific risk characteristics that are sources of managerial flexibility and, in consequence, value. These characteristics involve e.g.,

- options of producing different end-products,

- relatively easy carbon dioxide separation (based on direct coal combustion),

- processing different types of coal.

The first characteristic allows for switching between final products within the same technology. This flexibility arises from the fact that the process resulting in synthesis gas is only an intermediate product which in further processes-depending on market needs—can be appropriately conditioned and converted into different final products. This, due to relatively easy purification and enrichment of synthesis gas, can be electricity and heat, hydrogen, methanol, or liquid fuels. This means that by maintaining or slightly modifying the basic parameters of the coal gasification process, managers can develop different syngas conversion technologies within the same installation.

There are two methods of valuation that can capture the flexibility value and deliver a strategic (or so called 'expanded NPV'- 'XNPV') value of a project:

- Bayesian decision making (or decision tree analysis, DTA), and

- real options analysis, ROA (also called real options valuation, ROV).

Both of these reflect on the fact that a project manager-depending on the market situation-has the right (but not the obligation) to take measures on real assets. Economists prefer the ROA technique because the DTA method violates the law of one price and uses objective probabilities even in situations where consecutive decisions change the risk structure of the project [11].

ROA methodology is constantly growing in popularity: until the mid-90s it was familiar only within narrow scientific circles, but in recent decades the perception of its algorithms has changed dramatically and is widespread. Since the beginning of the century, companies have been also drawing increasing attention to real options valuation-in return there have been several publications (e.g., [11-13]) and impactful papers in this field. Currently the approach is often used as an alternative and complementary method to DCF analysis-especially for high-risk innovative ventures.

Due to the fact that coal gasification is a technology that has specific high-risk features that make it flexible to manage — especially to switch between end-products—we decided to formulate the following research questions:

- Is the ROA suitable tool for valuing coal gasification technologies-especially for evaluating switching options?

- How well the ROA—from a practical point of view—works in the case?

- How big the value of flexibility in that case could be?

We also decided to develop an original methodology suitable to value switching options.

In this context, the main contributions of the paper are threefold:

(1) identification of the appropriate switching option in the most important coal gasification ventures,

(2) systematization of the methods of calculation of the value of the two types of switching options:

(a) to mothball vs. to reopen production,

(b) to switch between final products, and

(3) valuation of the latter option in a hypothetical coal gasification plant in Poland.

The rest of this paper is organized as follows. Section 2 features a literature review. Section 3 develops a proposed valuation methodology for specific gasification projects. Section 4 presents calculations, results, and discussion. Finally, the paper ends with summary and conclusions. 


\section{Literature Review}

One of the first papers on the use the ROA for coal gasification technologies is Herbelott's paper from 1994 [14]. The study analyzed the case of a natural gas combined cycle (NGCC) power plant with an option to build a coal gasification plant for producing natural gas. The processes of two variables were simulated: prices of coal and natural gas. The option value was calculated using a discrete binomial model (underlying asset: the gross present value (PV) of the project, exercise price: capital expenditure). The strategic value of the gasifier investment (including the option-to-wait and the option-to-interrupt the operation) was found to be substantial—calculations showed that installing the gasifier at $t=0$ was not attractive to the utility.

The issue of the use of real option pricing has been widely described in the report [15] supporting strategic decision-making in the energy sector in Belgium where the option approach to select the best moment for the investment under uncertainty was presented (option-to-wait). An analysis of two projects was delivered: integrated gasification combined cycle (IGCC) and combined cycle gas turbine (CCGT). The optimal timing for IGCC conversion was calculated at year 7 of the period analyzed. The Black-Scholes-Merton continuous model was used [16,17]. As the underlying asset was assumed to have a gross present value (PV), the exercise price was the capital cost for rebuilding the installation. The waiting option was also evaluated by Reedman et al. [18] and Yang and Blyth [19].

Sekar [20] analyzed three alternative technologies for producing electricity: a classic pulverized coal (PC) boiler, IGCC plant, and an IGCC unit ready to install a carbon capture and storage (CCS) module. That author evaluated projects using DCF analysis and the ROA approach, assuming variations of one parameter (the $\mathrm{CO}_{2}$ allowance price). An option-to-wait was analyzed (continuous model, an option lifetime of 40 years, underlying asset: PV, exercise price: capital expenditure for the extension of the installation).

Laurikka [21] estimated a value of combined cycle coal gasification project and developed a simulation model using the real options approach, considering $\mathrm{CO}_{2}$ emissions trading scheme. Three stochastic variables were incorporated: the electricity price, fuel price, and the price of $\mathrm{CO}_{2}$ allowances.

The influence of $\mathrm{CO}_{2}$ prices on the selection of the appropriate gasification technology of electricity production also was dealt with by Yun and Baker [22]. They summarized that IGCC-related to the nuclear power plant-was not a preferable technology under the $\mathrm{CO}_{2}$ trading mechanism. The continuous model was used (option-to-wait, underlying asset: PV, exercise price: capital expenditure).

Teng et al. [23] analyzed the valuation of the project combining coal gasification and Fischer-Tropsch synthesis to produce liquid fuels (coal-to-liquids, CTL). Using a stochastic simulation of a process of oil prices and using the binomial tree, they calculated the option-to-wait (underlying asset: PV, exercise price: CAPEX).

The interesting type-specific real instrument for coal gasification technologies turns out to be the switching option. Kulatilaka [24] analyzed switching between a flexible technology (oil or natural gas) and two inflexible power generation technologies. Kutatilaka and Trigeorgis [25] considered option-to-switch between different fuels (oil or natural gas). Option in question was also examined by Abadie, Chamorro [26] who investigated (using a discrete binomial model) the possibility of altering the operating mode from coal IGCC to natural gas. Ammerlaan [27] discussed that option in terms of synthesis gas plant. The same option and fuels were considered by Gatfaoui [28].

Managerial flexibility then involved a choice between two available actions:

- leaving the current technology unchanged-in this case the value of the project equals the sum of the total profits generated by the coal unit over the period examined and the present value of the original (coal) project with the option-to-switch to gas, 
- switching to the original fuel-the project's value at this state is then the sum of the profits generated by the gas unit during the period examined and the present value of the gas alternative with the option-to-alter to coal, less the costs of switching.

Option-to-switch between different products in a bioenergy cogeneration project was analyzed by De Oliveira et al. [29]. Then Abadie [30] continued their studies on valuation of an operating coal-fired power station and a natural gas with the use of switching options exercised in cases when the electricity price was higher than variable costs (emissions, fuel, operation and maintenance). An interesting concept on switching option concerning CCGT (shutting down and restarting of gas-fired blocks) was developed by Kryzia et al. [31]. Other papers on fuel switch options were written lastly by Kujanpää and Pursiheimo [32] (switching from coal to biomass, natural gas to biomass, fuel oil to pyrolysis oil), Han et al. [33] (replacing coal with alternative fuels-natural gas, biomass, oil, electric boilers), Ghoddusi [34] (option to change gasoline at times to crude oil), Elias et al. [35], Fan et al. [36], and other authors.

In the most general case analysts calculate the strategic value, when at each point in time of the period analyzed the investor can choose between:

- investing in the NGCC,

- investing in the IGCC unit having the possibility to switch to a different fuel,

- ultimately abandoning the project.

The issue of the switching option in coal gasification technologies is reduced to the valuation of the managerial flexibility associated with the ability to switch between different fuels: coal, natural gas, peat, etc. The technology most commonly used is the IGCC installation. The case of switching between the different end products was not analyzed.

\section{Methods and Data-Valuation of Classic Switching Options}

In the real options theory switching is defined as the ability to change-at a specified cost-the status of the investment project between two states. The most important difference in reference to standard options is the assumption that there is the possibility of returning to the initial state-each time, when a company switches from state no. 1 to state no. 2, there is also the option of switching back to state no. 1. In our paper we considered two switching options:

1. option to mothball and to restart operations, and

2. option-to-switch between different outputs.

We applied the generalized 'MAD' approach proposed by Copeland and Antikarov [11] that provides a significant simplification of ROA algorithms. In our case this approach included:

- incorporating a binomial tree as a discrete model approximating a continuous time stochastic process,

- introducing — as an underlying instrument-a single project parameter (price of final product) that changes over time with consolidated volatility,

- making the following assumptions:

$\bigcirc$ the underlying asset changes according to a multiplicative binomial process [37],

$\bigcirc \quad$ volatility and a risk-free rate are constant throughout the lattice,

0 identification of a market traded twin security, securing 'no arbitrage' valuation, is unrequired-the twin asset of a project is the same project—but without managerial flexibility i.e., 'static' PV/NPV).

\subsection{Option to Mothball and to Restart Operations}

The mothballing vs. restarting problem is related to switching between activities 'in operation' and stopped. The management, depending on the market situation, may decide to temporarily shut 
down operations when the levels of product prices are too low (or costs are too high) and-if future prices increase (or costs decrease)—production can then be restarted again.

The switching option can thus be understood as a complex option. In this case it is a combination of the mothball (put) and reopen (call) options. The underlying assets of that compound option are annual revenues, and the exercise prices are as follows:

- $\quad$ saved annual variable costs, reduced by costs associated with the process of temporarily shutting down production-in the case of the option to mothball,

- sum of the restarting costs and annual variable costs.

Assuming a $N$-year period of operation, each year a company generates revenues $P$, incurring fixed costs $C_{F}$ and variable costs $C_{V}$. In the $N+1$ year, the project must be completed, and during this time the company can suspend and resume production any number of times. At any time, if the facilities are open, the company may shut down production at a suspension $\operatorname{cost} C_{s}$. During the period of mothballing, revenues and variable costs disappear-only fixed costs are incurred. At any time, the company may reopen production at a resumption $\operatorname{cost} C_{R}$.

Assuming that the price of the product is more variable than any respective factors associated with costs, at each $i$-node of the binomial tree for a specific period $n$, the company will generate revenues $R(i, n)$. In each subsequent period, they can increase to the value of $R(i, n+1)$ or fall to the value of $R(i+1, n+1)$.

When the company operates in period $n=0$, it might make one of two possible decisions: to mothball facilities or to continue production. When in period $n=0$ a decision has been made to suspend operations, the management will have to pay the suspension $\operatorname{cost} C_{s}$ and during period $n=1$ all facilities will be shut down - in such a situation the company does not generate any revenues, paying fixed costs. In the opposite situation, the company generates revenues incurring fixed and variable costs-in period $n=1$ continuing operations.

In period $n=1$ then, the company may be in one of two states, depending on the decision made during period $n=0$. If the production was mothballed, the management may decide to restart operations or wait; if they decide to reopen, they have to pay the resumption costs-during period $n=$ 2 the company continues to operate, generating revenues and incurring fixed and variable costs. In the opposite situation, if in period $n=0$ the decision to wait was made, then in period $n=1$ the CEOs have again two options: to temporarily shut down operations or to continue production.

Therefore, in every period $n=2, \ldots, N$, the company may exist in one of two states: with facilities mothballed or remaining operational. In the latter position, the management may suspend production or continue it; otherwise when the activity is paused, the management can reopen production or wait. In a subsequent period $n=N+1$, the company can also-theoretically-be in one of two states, but further production is no longer possible.

Due to the fact that in each period the company can exist in one of two states, it is necessary to build two trees of the option value-one for each state of the project. For every 'in operation' node ( $i$, $n)$, the project value will be equal $V_{P}(i, n)$, and for the suspended production $V_{S}(i, n)$.

As that production is possible only until $n=N$, in the period $n=N+1$-in both cases-the company's assets are worthless. Then the conditions for each node $i=0,1, \ldots, N+1$ are

$$
V_{P}(i, N+1)=V_{S}(i, N+1)=0
$$

Considering the case of 'in operation', in each period up to $n$ the managers have to make one of two decisions:

- maintain the facilities operational-the company will then generate cash flows equal to the difference in revenues $R(i, n)$ and sum of the fixed $C_{F}(n)$ and variable $\operatorname{costs} C_{V}(n)$; after one period (production still continuing), the value of the project will be $V_{P}(i, n+1)$ in the case of moving up the binomial tree (with probability $p(i, n)$ ), and $V_{P}(i+1, n+1)$ when moving down (with 
probability $g(i, n))$; assuming the risk-free rate is $r_{f}$, the value of the project in such a situation will be

$$
R(i, n)-C_{F}(n)-C_{V}(n)+\frac{p(i, n) V_{P}(i, n+1)+g(i, n) V_{P}(i+1, n+1)}{1+r_{f}}
$$

- cease the production activity - the company pays a single set of suspension costs $C_{S}(n)$ and the fixed $\operatorname{costs} C_{F}(n)$; after one period (activity paused) the value of the project will be $V_{S}(i, n+1)$ in the case of moving up the tree (with probability $p(i, n))$ and $V_{S}(i+1, n+1)$ in the case of moving down (with probability $g(i, n)$; the value of the project in such a situation would be

$$
-C_{S}(\mathrm{n})-C_{F}(i, n)+\frac{p(i, n) V_{S}(i, n+1)+g(i, n) C_{S}(i+1, n+1)}{1+r_{f}}
$$

Due to the principle of maximizing the benefits, the management will take such action as gives the greater payoff. It follows, that for each period $n=N, \ldots, 1,0$ the recursive equation is

$$
\begin{aligned}
V_{P}(i, n)= & \max \left\{R(i, n)-C_{F}(n)-C_{V}(n)+\frac{p(i, n) V_{P}(i, n+1)+g(i, n) V_{P}(i+1, n+1)}{1+r_{f}} ;\right. \\
& \left.-C_{S}(n)-C_{F}(n)+\frac{p(i, n) V_{S}(i, n+1)+g(i, n) V_{S}(i+1, n+1)}{1+r_{f}}\right\}
\end{aligned}
$$

Considering the case of mothballed production, in each period up to $n$ the CEOs have to make one of two decisions:

- leave the business in the current state-the company remains paying fixed costs $C_{F}(n)$; after one period (production still suspended), the value of the project will be $V_{S}(i, n+1)$ when moving up the binomial tree (with probability $p(i, n)$ ), and $V_{S}(i+1, n+1)$ in the case of moving down (with probability $g(i, n))$; the value of the project would be

$$
-C_{F}(n)+\frac{p(i, n) V_{S}(i, n+1)+g(i, n) V_{S}(i+1, n+1)}{1+r_{f}}
$$

- restart operations-the company pays the resumption costs $C_{R}(n)$, but annual cash flows occur equal to the difference in revenues $R(i, n)$ and the sum of the fixed $C_{F}(n)$ and variable costs $C_{V}(n)$; after one period (activity 'in operation'), the value of the project will be $V_{P}(i, n+1)$ in the case of moving up the tree (with probability $p(i, n)$ ) and $V_{P}(i+1, n+1)$ when moving down (with probability $g(i, n))$; the value of the project in such a situation would be

$$
-C_{R}(n)+R(i, n)-C_{F}(n)-C_{V}(n)+\frac{p(i, n) V_{P}(i, n+1)+g(i, n) V_{P}(i+1, n+1)}{1+r_{f}}
$$

For each period $n=N, \ldots, 1,0$ the recursive equation takes the form:

$$
\begin{gathered}
V_{S}(i, n)=\max \left\{-C_{F}(n)+\frac{p(i, n) V_{S}(i, n+1)+g(i, n) V_{S}(i+1, n+1)}{1+r_{f}} ;\right. \\
\left.-C_{R}(n)+R(i, n)-C_{F}(n)-C_{V}(n)+\frac{p(i, n) V_{P}(i, n+1)+g(i, n) V_{P}(i+1, n+1)}{1+r_{f}}\right\}
\end{gathered}
$$

Equation (4) shows that the value of the project with facilities in operation depends on its value in the following period when mothballed. Similarly, analyzing Equation (7), we can see that the value of the dormant project depends on the value of the operating one in the following period. It follows, that to build trees of option values $V_{P}(i, n)$, and $V_{S}(i, n)$, one must calculate both lattices simultaneously. The summary of the payoff functions at the time of exercise of the respective options is presented in Table 1, the idea of such an option is presented in Figure 1. 


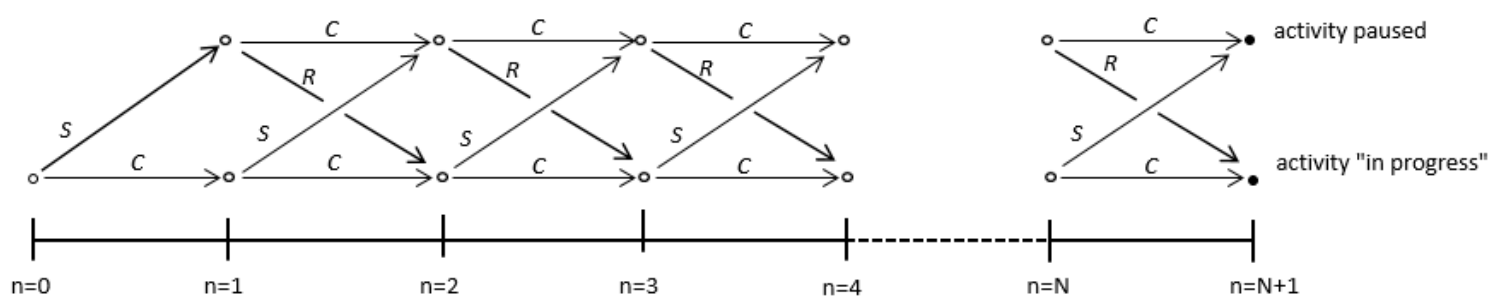

Figure 1. The concept of switching between modes to-mothball and to-reopen production facilities (source: own study).

\subsection{Option-To-Switch Outputs}

The mothballing vs. restarting problem can be expanded. As we mentioned before, a generalized problem of the switching option is associated with the ability to transition from the base state A in any state $B$ and back. That also means there is a possibility of switching between outputs.

Assuming that the states $\mathrm{A}$ and $\mathrm{B}$ are associated with fabricating two alternative products $\mathrm{A}$ and $\mathrm{B}$, and the period of operation is $N$ years, in each year the company can generate revenues from the sale of one of these products. At any time, if the current activity is focused on product $A$, the company may stop the current production and switch to the manufacture of product $B$, incurring the switching costs $C_{B}$. At a time when the business is focused on product $\mathrm{B}$, the project will generate revenues related to the sale of that product $\left(R^{B}\right)$, net of the corresponding fixed $\left(C_{F}^{B}\right)$ and variable $\left(C_{V}{ }^{B}\right)$ costs, and additionally the fixed costs $\left(C_{F}{ }^{A}\right)$ associated with the maintaining of the item A production lines. In any period, in which the activity is concentrated on product $B$, the company may reverse past actions.

Assuming that the prices of the manufactured products are more variable than the individual factors associated with the costs, at each $i$-node of the binomial tree for a specific period $n$, the company can generate revenues $R^{A}(i, n)$ when making product $\mathrm{A}$, or $R^{B}(i, n)$ in the opposite situation. In each subsequent period, revenues may increase to the value of $R^{A}(i, n+1)$ or $R^{B}(i, n+1)$ or fall to the value of $R^{A}(i+1, n+1)$ or $R^{B}(i+1, n+1)$.

Assuming that in the period $n=0$ our company is focused on the production of the base product A, the management might make one of two possible decisions: to switch their activity to product $\mathrm{B}$, or continue manufacturing product $\mathrm{A}$. When in period $n=0$ the decision to switch was taken, the company has to pay the costs of switching $C_{B}$ and in period $n=1$ it continues manufacturing product $\mathrm{B}$, generating revenues $R^{B}$ along with incurring the costs: $C_{F}{ }^{B}, C_{V}{ }^{B} \mathrm{~B}$, and $C_{F}{ }^{A}$. In the opposite situation (continuing to manufacture product $\mathrm{A}$ ), the company generates revenues of $R^{A}$, incurring the costs: $C_{F}{ }^{A}, C_{V}{ }^{A} \mathrm{~B}$, and $C_{F}{ }^{B}$.

In period $n=1$, then, the company may operate in one of two states each of which is dependent on the decision taken during the period $n=0$. If in that period the production was switched to product $\mathrm{B}$ (which naturally means paying the cost of switching $C_{B}$ ), the management may now decide to return to manufacturing product $A$ or continue the production of product $B$. In the opposite situation, when in period $n=0$ a decision was made to continue manufacturing product $\mathrm{A}$, in $n=1 \mathrm{CEO}$ have again two options: to switch output to product B (incurring the cost of switching) or wait.

Therefore, it stands to reason that in every period $n=2, \ldots, N$ the company may be in one of two states: production of item A or of item B. We also set an assumption that in period $n=N+1$ the company can also- theoretically—be in one of two states, but further production is no longer possible.

Similarly, as in the case of the problem of mothballing vs. restarting output, it is necessary to build two binomial trees of option value-one for each state of the project. For each node $(i, n)$, when the company is manufacturing product $\mathrm{A}$, the project value will be equal to $V_{A}(i, n)$, while in the case of the production of item $\mathrm{B}, V_{B}(i, n)$. 
As production is only possible until $n=N$, in period $n=N+1$-in both cases-the company's assets are worthless. The final conditions for each node $I=0,1, \ldots, N+1$ are

$$
V_{A}(i, N+1)=V_{B}(i, N+1)=0
$$

Considering the case of product A, in each period to $n$ the company CEOs must make one of two decisions:

- leave the business in the current state-the company will then generate cash flows equal to the difference between revenues $R^{A}(i, n)$ and sum of the costs: $C_{F}{ }^{A}(n), C_{V}{ }^{A}(n)$, and $C_{F}{ }^{B}(n)$; after one period, the value of the project will be $V_{A}(i, n+1)$ when moving up the binomial tree (with probability $p(i, n)$ ) and $V_{A}(i+1, n+1)$ in case of moving down (with probability $g(i, n)$ ); assuming the risk-free rate is $r_{f}$, the value of the project in such a situation will be

$$
R^{A}(i, n)-C_{F}^{A}(n)-C_{V}^{A}(n)-C_{F}^{B}(n)+\frac{p(i, n) V_{A}(i, n+1)+g(i, n) V_{A}(i+1, n+1)}{1+r_{f}}
$$

- switch production - the company pays the switching costs $C_{B}(n)$-that means, in consequence, disappearing revenues $R^{A}(i, n)$ and variable $\operatorname{costs} C_{V}^{A}(n)$ related to product $\mathrm{A}$, but cash flows occur associated with product $\mathrm{B}$, equal to the difference in revenues $R^{B}(i, n)$ and the sum of the costs $C_{F}{ }^{B}(n), C_{V}{ }^{B}(n)$ and $C_{F}^{A}(n)$. After one period the project value will be $V_{B}(i, n+1)$ in the case of moving up the tree (with probability $p(i, n))$ and $V_{B}(i+1, n+1)$ when moving down (with probability $g(i, n))$. The value of the project in such a situation would be

$$
-C_{B}(n)+R^{B}(i, n)-C_{F}^{B}(n)-C_{V}^{B}(n)-C_{F}^{A}(n)+\frac{p(i, n) V_{B}(i, n+1)+g(i, n) V_{B}(i+1, n+1)}{1+r_{f}}
$$

Considering the principle of maximizing benefits, the management would take such action as may be necessary to provide the greater payoff. It follows, that for each period $n=N, \ldots, 1,0$ the recursive equation is

$$
\begin{gathered}
V_{A}(i, n)=\max \left\{R^{A}(i, n)-C_{F}^{A}(n)-C_{V}^{A}(n)-C_{F}^{B}(n)+\frac{p(i, n) V_{A}(i, n+1)+g(i, n) V_{A}(i+1, n+1)}{1+r_{f}}\right. \\
\left.-C_{B}(n)+R^{B}(i, n)-C_{F}^{B}(n)-C_{V}{ }^{B}(n)-C_{F}^{A}(n)+\frac{p(i, n) V_{B}(i, n+1)+g(i, n) V_{B}(i+1, n+1)}{1+r_{f}}\right\}
\end{gathered}
$$

In the case of product $\mathrm{B}$, in each period to $\mathrm{n}$ the management must make one of two decisions:

- leave the business in the current state-the company will then generate cash flows associated with item $B$ equal to the difference in revenues $R^{B}(i, n)$ and sum of the costs: $C_{F}{ }^{B}(n), C_{V}{ }^{B}(n)$ and $C_{F}{ }^{A}(n)$. After one period, the value of the project will be $V_{B}(i, n+1)$ when moving up the tree (with probability $p(i, n)$ ), and $V_{B}(i+1, n+1)$ in the case of moving down (with probability $g(i, n)$ ). Assuming the risk-free rate is $r_{f}$, the value of the project in such a situation will be

$$
R^{B}(i, n)-C_{F}^{B}(n)-C_{V}^{B}(n)-C_{F}^{A}(n)+\frac{p(i, n) V_{B}(i, n+1)+g(i, n) V_{B}(i+1, n+1)}{1+r_{f}}
$$

- switch production to an alternative product - the company then pays the switching $\operatorname{costs} C_{A}(n)$, with the result that the revenues $R^{B}(i, n)$ and variable costs $C_{V} B(n)$ disappear, while annual cash flows occur equal to the difference in revenues $R^{A}(i, n)$ and the sum of the costs: $C_{F}{ }^{A}(n), C_{V}{ }^{A}(n)$, and $C_{F}{ }^{B}(n)$. After one period the project value will be $V_{A}(i, n+1)$ in the case of moving up the 
tree (with probability $p(i, n))$ and $V_{A}(i+1, n+1)$ when moving down (with probability $g(i, n)$ ). The value of the project in such a situation would be

$$
-C_{A}(n)+R^{A}(i, n)-C_{F}^{A}(n)-C_{V}^{A}(n)-C_{F}^{B}(n)+\frac{p(i, n) V_{A}(i, n+1)+g(i, n) V_{A}(i+1, n+1)}{1+r_{f}}
$$

For each period the $n=N, \ldots, 1,0$ recursive equation takes the form:

$$
\begin{gathered}
V_{B}(i, n)=\max \left\{R^{B}(i, n)-C_{F}^{B}(n)-C_{V}^{B}(n)-C_{F}^{A}(n)+\frac{p(i, n) V_{B}(i, n+1)+g(i, n) V_{B}(i+1, n+1)}{1+r_{f}}\right. \\
\left.-C_{A}(n)+R^{A}(i, n)-C_{F}^{A}(n)-C_{V}^{A}(n)-C_{F}^{B}(n)+\frac{p(i, n) V_{A}(i, n+1)+g(i, n) V_{A}(i+1, n+1)}{1+r_{f}}\right\} .
\end{gathered}
$$

Similarly, as in the case of the mothballing/restarting problem, in order to build trees of option values $V_{A}(i, n)$, and $V_{B}(i, n)$, one must calculate both trees simultaneously. A summary of payoff functions at the time of exercising individual options is presented in Table 1, the concept of such an option is presented in Figure 2.

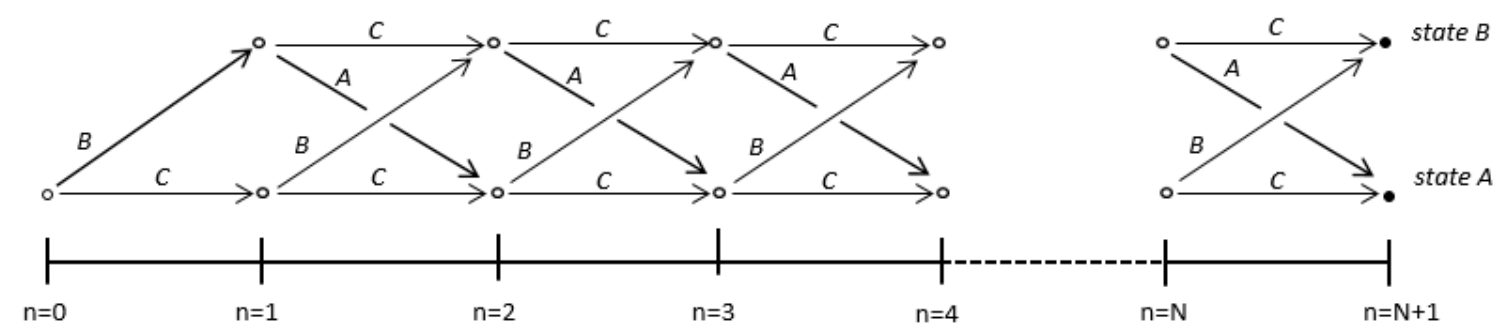

Figure 2. The concept of the output switching option (source: own study).

The problem of switching between different inputs is analogous to the case of switching between the final products. In this case, it is assumed that the prices of certain inputs (raw materials, fuels, intermediates), which are associated with variable costs, are the most variable and their changes are simulated.

In addition to the options discussed above, the switching option may also be related to the manufacture of the product on different machines. The switching problem may also be extended to more than two states (e.g., regular production, expanded production, contracted production) along with defined sequences associated with the change from one status to another.

The types of switching options discussed above are those cases associated with the problem of switching between different functioning states of a company that are analyzed most frequently. This is due to the fact that in each period the project can go in one of the available states, and some states may occur more than once which is what most clearly distinguishes them from other option problems. That kind of managerial flexibility can be a meaningful source of strategic value for a company.

\section{Results and Discussion}

In this section, the option-to-switch between outputs for a hypothetical integrated coal gasification plant is valued using the binomial tree method [38]. First, the base cases were considered taking into account standard cash flow analysis for electricity and methanol production. A traditional NPV was calculated for these separate projects. Next, the option mentioned was valued using the multiplicative stochastic process for the underlying uncertainty. The ability to switch between final products involves additional costs. When management decides to switch production from electricity to methanol, the company has to incur switching costs and to pay fixed costs related to the unused electricity module. The same situation will occur during reverse switching, although the costs will be correspondingly different. Finally, a comparison between the results obtained is presented to show the difference between using each model in the valuation of coal gasification projects. 
Table 1. Payoff functions for switching options (source: own study based on $[39,40]$ ).

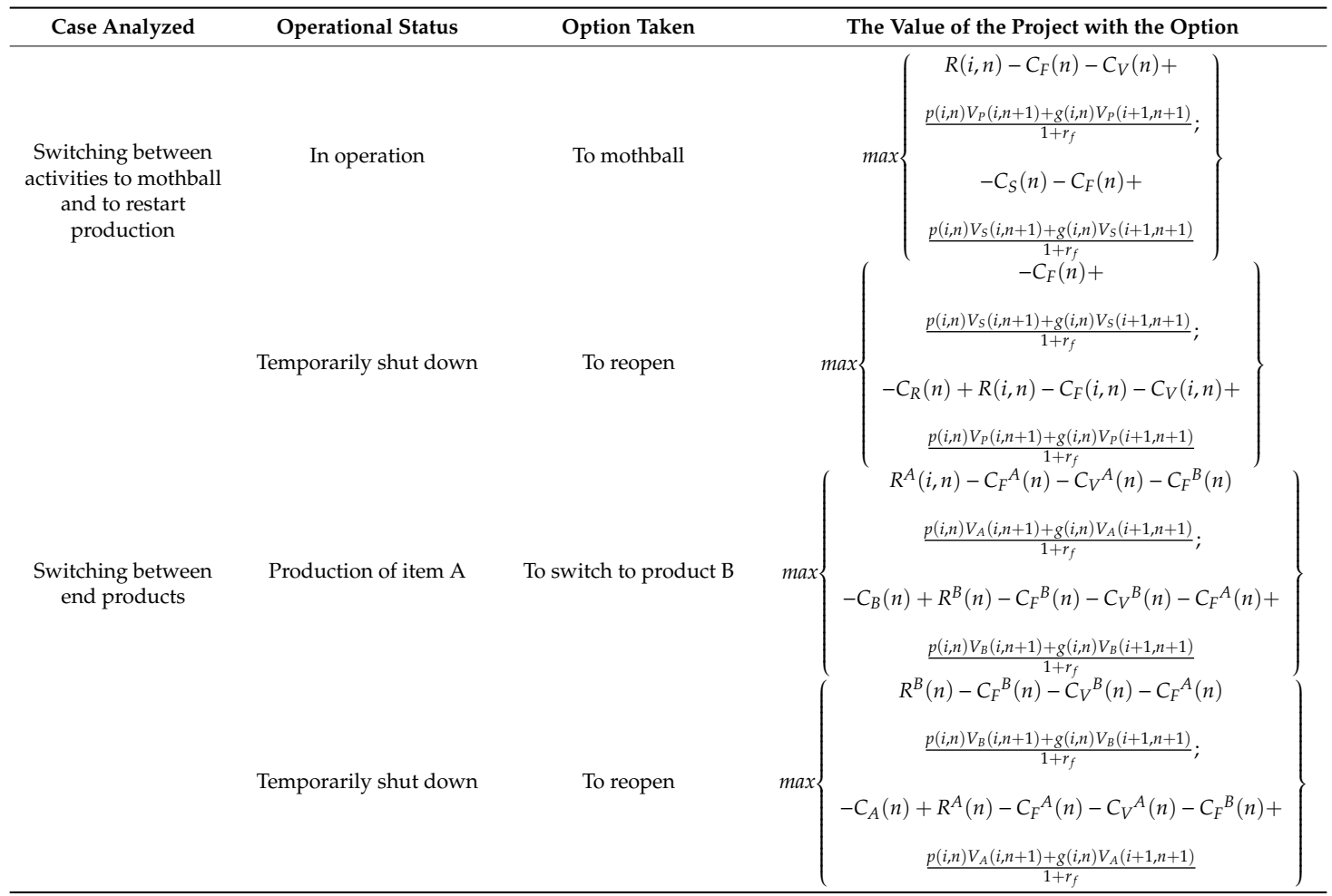

$N$-expiration time (number of periods in the tree of changes of the underlying asset value); $n=N, \ldots, 1,0$-period in the tree; $i=0,1, \ldots, N+1-$ number of the node for a specific period $\mathrm{n} ; V$-an option value of the project; $R$-annual revenues; $C_{F}, C_{V}$-annual fixed and variable costs; $C_{S}, C_{R}, C_{B}, C_{A}$ - cost of changing the status of activities; $p$ - probability of increase in value of the underlying asset; $g$ - probability of decrease in value of the underlying asset; $r_{f}$-risk-free discount rate.

\subsection{Case Study: Valuing the Option to Switch between End Products for a Coal Gasification Plant}

The value of flexibility to switch between different outputs may be, as we stated above, an important source of strategic value for coal gasification projects. This is because different gasification products might be mutably, but sometimes strongly, demanded by different sectors of the industry. When market conditions are not favorable, managers of such projects have a real option to change their primary output to a final product (methanol, hydrogen, ammonia) that results in higher profits, even if temporarily. The calculation of the option value begins with a cash flow simulation in which possible chains of technological processes will be tested in diverse scenarios of end product prices. To calculate this value, three hypothetical variant technologies were considered (located in Poland), all based on hard coal, using the Shell gasifier without the possibility of capture and sequestration of carbon dioxide (CCS).

- the electricity project-product: electricity,

- the methanol project-product: methanol,

- the integrated plant-products: electricity and methanol.

A methodology of calculation is as follows: first, the traditional ('static') NPV value is calculated based on discounted cash flow analysis, separately for both projects (electricity, methanol). Then, assuming that the end product process follows the geometric Brownian motion (more specifically: its discrete approximation in the form of a multiplicative stochastic process), two binomial trees of electricity and methanol prices are developed for an integrated plant. Clearly it refers to a complex rainbow option with two sources of uncertainty, where both end product prices are called 'reference underlying instruments' and the resulting project cash flows are referred as 'consecutive underlying instruments' [39]. Based on these, a tree of changes of consecutive instruments is constructed and 
the value of the switching option is finally determined. If the management decides to switch from methanol to electricity, the company must bear the cost of switching and the fixed costs associated with maintaining the unused power generation unit. A similar situation occurs when switching in the reverse direction (Table 1). Finally, a summary of the results is presented to illustrate the applicability of using various methods for the valuation of coal gasification projects.

\subsection{Base Cases}

As already mentioned, we considered two hypothetical coal gasification projects in Poland, built at the same time and with the following parameters:

- installations are based on the Shell gasifier, without a CCS capture system,

- fuel: hard coal with a heat value of $20.22 \mathrm{GJ} / \mathrm{Mg}$,

- operating scale: $100 \mathrm{Mg} / \mathrm{h}$,

- first installation: equipped with a module for electricity production with a maximum yearly capacity of 1,790,430 MWh,

- second installation: equipped with a methanol synthesis module with a maximum yearly capacity of $502,580 \mathrm{Mg}$,

- capacity factors: $80 \%$ for electricity and $90 \%$ for methanol,

- capital expenditures:

electricity plant: $3,195.7$ million PLN $(1$ PLN $=0.22-0.24 €)$ in present value at the time of project startup,

○ methanol synthesis plant: 3,099.8 million PLN.

We assumed the following periods of plant lifetime:

- construction period 3 years,

- operating period 30 years, where the first year is a start-up phase and the last year is a plant closure phase,

We also assumed that capital expenditures will fully depreciate and amortize within 30 years (straight line depreciation/amortization) and that residual value was zero.

Therefore, we calculated a yearly cash flow for a 33-year time span.

Calculations were conducted in nominal values; an inflation rate of $2.5 \%$ was assumed. The nominal effective risk-adjusted discount rate (RADR), assuming $100 \%$ financing of capital expenditure, is $11 \%$. At the time of the analysis (year " 0 "), the price of electricity is $190 \mathrm{PLN} / \mathrm{MWh}$ and the price of methanol is $1400 \mathrm{PLN} / \mathrm{Mg}$. A historical series analysis of electricity prices (past 14 years-Figure 3 ) shows an average growth rate of $6.1 \%$, and for methanol prices (past 14 years-Figure 4 ) $11.7 \%$ per year. Based on these data, it is assumed that the price trend of electricity is 3.46\% per year and the trend of methanol is $3.96 \%$ per year. In both technologies additional revenues related to the sale of heat are also included.

One of the main costs in coal gasification technologies is fuel cost (constituting about $50 \%$ of all operating costs). We assumed that the coal to be gasified is hard coal with a heating value of $20.22 \mathrm{GJ} / \mathrm{Mg}$. Let us assume its price was $210 \mathrm{PLN} / \mathrm{Mg}$. A historical analysis of Polish hard coal prices shows an average growth rate of $4.8 \%$ per year until year ' -1 ' (Figure 5). However, over the immediate 3 years before year ' 0 ', a decrease in hard coal prices could be observed. Therefore, based on forecasts available in international reports published by IEA, World Bank, etc. and our own calculations that also incorporate forecasts of domestic coal prices, we estimated the trend value as $2.46 \%$ (average annual increase). 


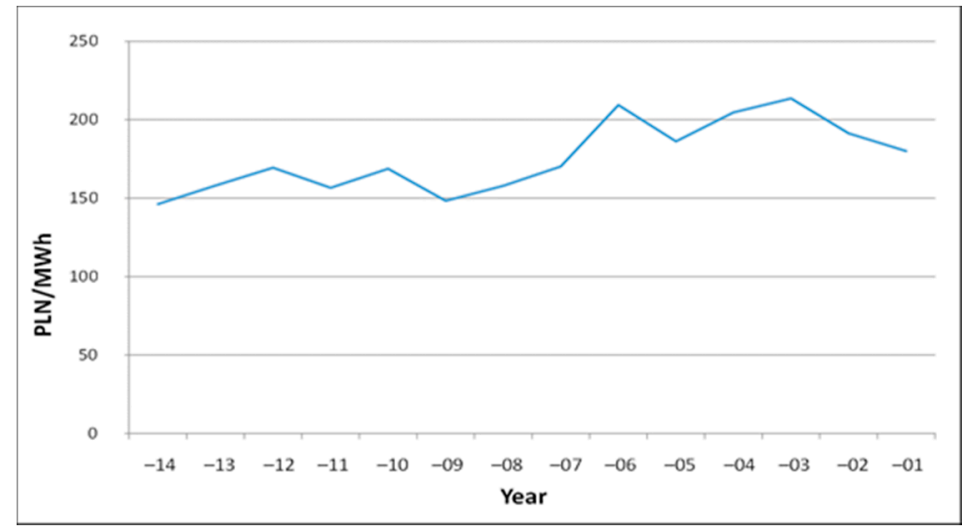

Figure 3. Wholesale electricity prices (nominal values) (source: [41]).

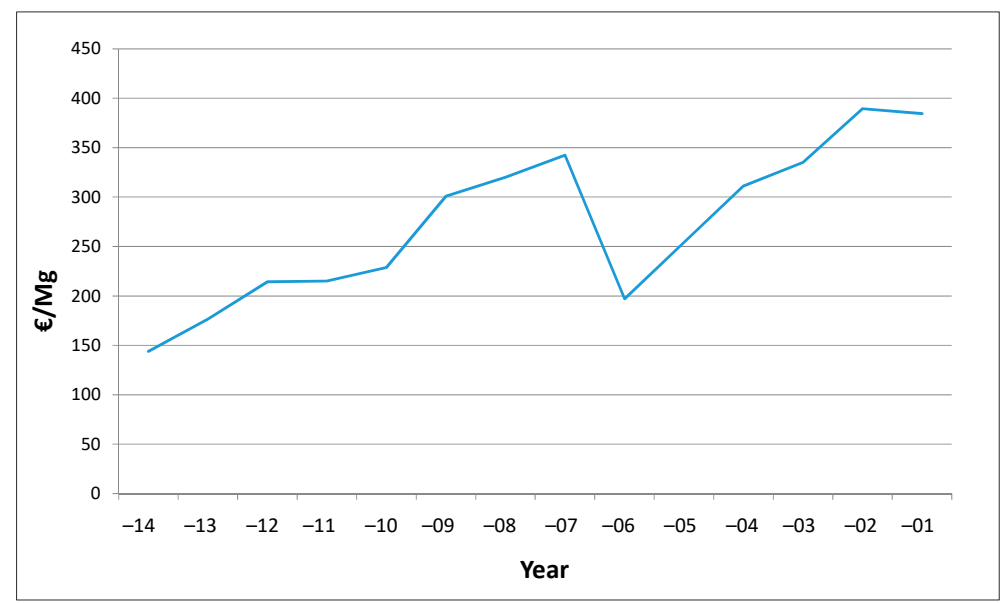

Figure 4. Methanol prices (nominal values) (source: [42]).

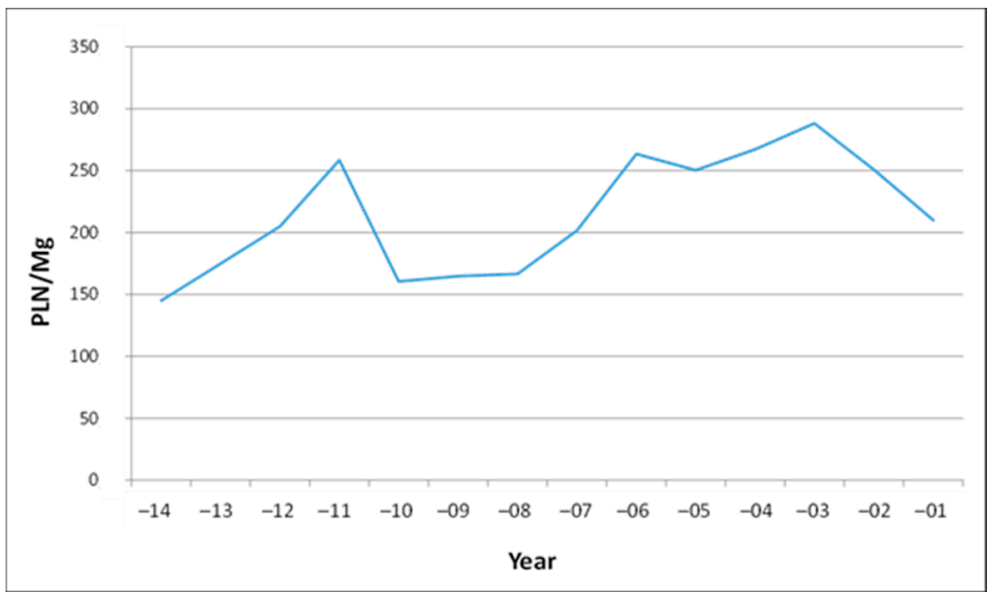

Figure 5. Hard coal prices (source: [43]).

The second important cost is the price of the $\mathrm{CO}_{2}$ emissions allowance. Its weight in operating costs is about $6 \%-10 \%$. We use the value of $3.46 \%$ as the trend (average annual increase). Other production costs (excluding energy and depreciation) are chemicals, water, maintenance, property taxes and insurance, environmental fees, manpower, and waste treatment. It is assumed that these costs grow at the same rate as inflation $(2.5 \%)$. 
We assumed that both plants are energy self-sufficient. It means that they produce exactly as much electricity as they need. The initial capital expenditure is linearly depreciated during the project's lifetime (30 years). Polish corporate tax is 19\%. The turnover of working capital is 30 days.

With these assumptions, the yearly net free cash flow is estimated by the equation:

$$
N F C F_{n}=\left[(1-T)\left(C \times P_{n}+A R_{n}-T O C_{n}\right)\right]+D_{n}-N W C_{n}-I_{n}
$$

where:

$N F C F_{n}$-net free cash flow in time $n=1, \ldots, 33$,

$T$-corporate tax rate,

C-plant capacity,

$P_{n}$-price of the final product at time $n$,

$A R_{n}$-additional revenues in time $n$,

$T_{O C}$-total operating costs (including coal, $\mathrm{CO}_{2}$ costs, and depreciation) in time $n$,

$D_{n}$-depreciation and amortization in time $n$,

$N W C_{n}$ —changes in net working capital in time $n$,

$I_{n}$-capital expenditures in time $n$.

The NPV of the expected cash flows at the effective risk-adjusted discount rate for the base variants was estimated at:

- electricity project: $-2,185.3$ million PLN,

- methanol project: -390.7 million PLN.

Thus, the value of both alternatives is negative. According to the DCF decision criterion (invest if NPV $>0$ ), investors would then decide not to build any of the base variants being considered on the basis of the values thus calculated.

\subsection{Option-to-Switch the End Product in the Integrated Plant}

The analysis of the classical NPV of both projects does not involve value of the managerial flexibility associated with the possibility of switching between final products. For example, when technology is mainly focused on the production of methanol, in some periods the output of hydrogen could be a more interesting, profitable option to the management and vice versa. To calculate the value of the option-to-switch between end outputs the real options approach was used.

Firstly, using the multiplicative stochastic process technique, two 33-year interval binomial trees of final product prices were constructed: one for the electricity price and one for the methanol price. This technique was used because it is easily accessible and allows one to calculate complex options such as a switching option.

A common CRR model of the discrete approximation of a continuous stochastic process of underlying assets was used [44]. In the original CRR model, the tree parameters are described by the formulas:

$$
\begin{gathered}
u=e^{\sigma \sqrt{t}} \\
d=e^{-\sigma \sqrt{t}} \\
p=\frac{e^{r} t-d}{u-d} \\
g=1-p
\end{gathered}
$$

where:

$u$-increase ratio in the multiplicative tree,

$d$-decrease ratio in the tree, 
$\sigma$-volatility of the underlying asset,

$t$-time interval,

$r_{f}$-risk-free discount rate,

$p$-probability of increase,

$g$ - probability of decrease.

Parameters of volatility were assessed by the standard deviation of the log return of the price sequences (the logarithmic stock price returns approach, LSPR) shown in Figures 3 and 4 -for electricity with a value of $\sigma=6.8 \%$ and for methanol $\sigma=22.1 \%$, respectively. This approach was used because it allows one to calculate the volatility based on historic data [45]. The risk-free rate was estimated at $4 \%$ (nominally). The time interval in the tree was 1 year.

Secondly, considering the binomial trees of prices (reference instruments), two corresponding trees of net CF (consecutive instruments) were built. The capital expenditure needed for the integrated plant was estimated at 3,795.7 million PLN. Another difference in the simulated cash flow is provided by the fixed operating costs related to unused modules, which are different for electricity and methanol production. It was assumed that costs associated with mothballed processes of electricity production are 4.4 million PLN and of methanol production 4.0 million PLN. For example, net free cash flow for methanol production is estimated by the equation:

$$
N F C F_{i, n}{ }^{M}=\left[(1-T)\left(C^{M} \times P_{i, n}{ }^{M}+A R_{n}{ }^{M}-T O C_{n}{ }^{M}-C U_{n}{ }^{E}\right)\right]+D_{n}{ }^{E M}-N W C_{n}{ }^{M}-I_{n}{ }^{E M}
$$

where:

$n=1, \ldots, 33$ - discrete intervals in the tree,

$(i, n)$ - the node $i$ in the tree in period $n$,

$C^{M}$-yearly capacity of methanol production,

$N F C F_{i, n}{ }^{M}$-net free cash flow in the case of methanol production in node $i$ in period $n$,

$P_{i, n}{ }^{M}$ - the price of methanol in node $i$ in period $n$,

$A R_{n}{ }^{M}$-additional revenues in the case of methanol production in period $n$,

TOC $_{n}{ }^{\mathrm{M}}$ - total operating costs (including coal, $\mathrm{CO}_{2}$ costs, and depreciation) in the case of methanol production in period $n$,

$\mathrm{CU}_{n}{ }^{E}$ - costs of unused modules dedicated to electricity production in period $n$,

$D_{n}{ }^{E M}$ —depreciation and amortization of integrated plant capital expenditure in period $n$,

$N W C_{n}{ }^{M}$-changes in net working capital in the case of methanol production in period $n$,

$I_{n}{ }^{E M}$ _investment in integrated plant in period $n$.

The consecutive instrument trees obtained in this way are not regular binomial trees, and their volatilities (probabilities of increase and decrease) are different from the parameters of the trees of price changes. To calculate the new probabilities $\left(p^{\prime}, q^{\prime}\right)$, respective trees of present value $(P V)$ were built. In the next step, probability $p^{\prime}$ in the $P V$ tree was estimated, so that the value of the starting node $P V_{0}$ was equal to the expected value $\mathrm{E}\left(P V_{0}\right)$ which was obtained using DCF analysis.

Lastly, two trees of output switching option value were built. One for the case in which the initial mode is electricity production, and the second one for the case in which the initial mode is methanol production. In this step, the switching costs have to be taken into account. It was assumed that the transition cost from electricity production to methanol production is 5.0 million PLN and 4.5 million PLN in the case of a backward switch.

It is important to point out that gasification projects are very risky. To be methodologically correct we should identify the project's twin securities that make it possible to build replicating portfolios, enabling risk-free option valuation. We are aware that such assets do not exist which makes option valuation impossible. To solve this problem, we assumed that prices are the dominant sources of our project risks, which have corresponding twin assets (forward/futures prices). We are aware of all the 
weaknesses and limitations of that assumption but in our view, it is not worse than others used in real options valuation (e.g., Marketed Asset Disclaimer). It now makes it possible to both construct the respective project replication portfolios and to undertake risk-free option valuation.

Of course, the other solution could be to apply real options algorithms but discounting the binomial tree cash flow values at a risk-adjusted discount rate or weighted average cost of capital, reduced by an allowance for the hedged price risk. However, such a calculation would turn real options valuation into Bayesian analysis, so we turned away from it.

The switching option is valued over a 34-year time span. In the case when the initial mode is methanol production, formulas in the tree nodes of particular periods are as follows:

- in the 34th period (year) the option value is equal to 0 , because after 30 years of operating, further production is not possible and the plant will be worthless,

- $\quad$ in the 4-33 periods, when decision flexibility exists:

$$
\begin{gathered}
V_{i, n}{ }^{M}=\max \left\{N F C F_{i, n}{ }^{M}+\frac{p^{M \prime} V_{i, n+1}{ }^{M}+g^{M \prime} V_{i+1, n+1}{ }^{M}}{1+r_{f}}\right. \\
\left.-S C_{n}{ }^{E}+N F C F_{i, n}{ }^{E}+\frac{p^{E \prime} V_{i, n+1}{ }^{E}+g^{\prime} V_{i+1, n+1}{ }^{E}}{1+r_{f}}\right\}
\end{gathered}
$$

where:

$V_{i, n}{ }^{M}$ - output switch option value in node $i$ in period $n$,

$V_{i, n+1}{ }^{M}$ _output switch option value in node $i$ in period $n+1$,

$p^{M \prime}, p^{E \prime}$-probability of increase in the tree of methanol/electricity price changes,

$g^{M \prime}, g^{E \prime}$ - probability of decrease in the tree of methanol/electricity price changes,

$S C_{n}{ }^{E}$-switching cost from methanol to electricity production.

- $\quad$ in the 1-3 periods, when there is a construction phase:

$$
V_{i, n}{ }^{M}=N F C F_{i, n}{ }^{M}+\frac{p^{M \prime} V_{i, n+1}{ }^{M}+g^{M \prime} V_{i+1, n+1}{ }^{M}}{1+r_{f}}
$$

- in the " 0 " period:

$$
V_{1,0}{ }^{M}=\frac{p^{M \prime} V_{1,1}{ }^{M}+g^{M \prime} V_{2,1}{ }^{M}}{1+r_{f}}
$$

The formulas for the case in which the initial mode is electricity production are analogues.

The investor can choose the initial state of the technology—thus the extended net present value of the project (strategic value) connected with the possibility to switch will then be:

$$
X N P V=\max \left\{V_{1,0}{ }^{M} ; V_{1,0}{ }^{H}\right\}=\{2,698.1 \text { million PLN; } 1,241.6 \text { million PLN }\}=2,698.1 \text { million PLN }
$$

As we stated earlier, for the base (DCF) cases of two hypothetical coal gasification plants in Poland, the net present value of 33 years of projected cash flows discounted at the effective risk-adjusted discount rate $(11 \%)$ amounts to:

- $\quad-2185.3$ million PLN in case of electricity production,

- $\quad-390.7$ million PLN in case of methanol production.

Finally, two trees of output switch option value were built, and the strategic net present value of the integrated plant was obtained:

$$
X N P V=\max \left\{V_{0,1}{ }^{E} ; V_{0,1}{ }^{M}\right\}=\max \{1,241.6 ; 2,698.1\}=2,698.1 \text { million PLN }
$$


Table 2 summarizes the values found for the electricity and methanol projects (classic NPVs), and the integrated plant (expanded net present value, XNPV) containing the value of the option-to-switch between end-products in the whole 30-year operating phase.

Table 2. Values of projects considered-net present values (NPVs) of methanol and electricity technologies and 'expanded NPVs' (XNPVs) of the integrated plant with option premiums (million PLN, year “0”) (source: own study).

\begin{tabular}{cccc}
\hline Item & NPV & $\begin{array}{c}\text { Integrated Plant } \\
\text { XNPV }\end{array}$ & Option Premium \\
\hline Electricity project & -2185.3 & 2698.1 & 4883.4 \\
Methanol project & -390.7 & & 3088.8 \\
\hline
\end{tabular}

The results obtained clearly show the difference between the methods used to evaluate economic efficiency. If the decision criterion which would arbitrate on whether to start the project immediately, or reject it, was the condition NPV $>0$, based on the established numbers, investors would not decide to engage in any of the projects considered. The situation is quite different when the decision criterion related to the theory of real options is in the form of a condition XNPV $>0$. Using the new, modified criterion, after analyzing the variant with the production of both final products and the valuation of the possibility of switching between them, it can be concluded that investment in this type of coal gasification technology becomes a desirable opportunity.

Our example demonstrates that gasification projects have dormant deep sources of value that traditional DCF analysis does not recognize. That value arises from the flexibility that helps managers effectively respond to rapidly changing market environment. Considering the value of flexibility investors might see gasification projects in a different light—as attractive investment opportunities, especially when constructing expandable, integrated plants.

We can see then, that the real options approach reveals itself as a suitable tool for valuing coal gasification technologies and that proposed methodology for valuing switching options is efficient and effective.

\section{Summary and Conclusions}

The concept of coal gasification has been known since the second half of the 19th century. It originates from the Siemens brothers and Mendeleev. Later on, the development of coal gasification technologies has mainly been driven by uncertainty in the fuel markets related to dramatic changes in oil and natural gas prices. Coal gasification is as an advanced clean energy alternative to conventional coal burning.

Coal gasification projects are inherently risky and volatile-they depict various specific features that differentiate them from alternative investments in other industries. The most important project-specific characteristics involve the possibilities of

- delivering different end-products-mainly electricity, but also methanol and its derivatives: Hydrogen and liquid fuels,

- relatively easier-as compared to classical power units (based on direct coal combustion)—carbon dioxide separation,

- $\quad$ processing various coal types with different quality parameters.

They involve several sources of managerial flexibility that influence the strategic value of the projects and should be evaluated. This flexibility provides management leeway to

- defer an investment (option-to-wait),

- modify the operational strategies (options: to-expand, to-shrink, to-mothball, to-restart, to-abandon) including 
$\bigcirc \quad$ altering the final product (switching between alternative products),

$\bigcirc$ extending the installation of carbon capture and storage,

$\bigcirc \quad$ changing the input fuel being processed,

$\bigcirc$ expanding or shrinking production,

$\bigcirc \quad$ abandoning the project.

Traditional DCF techniques cannot capture the value resulting from these opportunities and thus may undervalue coal gasification assets. Great potential, in terms of valuing these assets, is offered by real options analysis (ROA) that-as a complement to classical cash flow calculus-adjusts adequately for risk and allocates value to flexibility. Due to the fact that DCF analysis cannot provide a value of managerial flexibility, one can see confirmation of an increasing spreading of the application of ROA in various branches of mining industry (mainly minerals, oil and gas, coal) and in banking sector.

First attempts to use real options analysis for valuing coal gasification projects were made in the last years of the 20th century. With time, the number of applications of ROA has increased. Most of them considered the valuing of projects with option-to-defer and or option-to-abandon. The dominant technology was the surface coal gasification plant with an integrated gasification combined cycle, IGCC.

In this paper two baselines were analyzed and calculated using DCF-the first one was based on the production of electricity and the second one on the production of methanol. We expected that switching options may be substantial sources of managerial flexibility of coal gasification projects. Thus, real options analysis was used to calculate an integrated plant that can produce either electricity or methanol.

In the real options theory, switching is defined as the ability to change-at a specified cost-the status of the investment project between two states. This means that management has the possibility of switching from one state of operations to another (mothball-restart, alter outputs). The most important difference in reference to standard options is the assumption that there is the possibility of returning to the initial state.

The calculations deliver expanded net present value-strategic value of a project (XNPV) that is greater than zero and equals 2,698.1 million PLN. The result contrasts with the negative 'static' net present values (NPV) obtained for electricity and methanol projects ( -2185.3 and -390.7 million PLN, respectively). Thus, the value of managerial flexibility of coal gasification technologies may have a substantial dimension that can significantly support the decision-making process.

In our paper we demonstrated that real options analysis can be an adequate methodology for valuing coal gasification technologies-in particular for evaluating projects with options-to-switch, which is an interesting novelty. Our model is user-friendly and works successfully, so it can be applied in the industry. We showed that adequately employed binomial approach can be a successful methodology for valuing expandable gasification projects with switching options. It is an effective solution for companies and banks when considering various clean energy investment opportunities.

Real options calculus for gasification technologies requires adaptations of various models to the reality-that results in the appearance of further research. Stochastic modelling of volatility, calibrating and validating of developed real options models, calculation of compound options in multi lattices might be highly interesting for future investigations. Validation of real options models is a challenging exercise. Further extension of this paper may include model validation to be carried out with the support of an assessment process as recommended by Sterman [46] in order to test its dynamic nature.

Author Contributions: Conceptualization, P.W.S., P.G. and J.K.; methodology, P.W.S., P.G. and J.K.; software, P.G.; validation, P.W.S., P.G. and J.K.; formal analysis, P.W.S., P.G.; investigation, P.W.S., P.G. and J.K.; resources, P.W.S., P.G.; data curation, P.G.; writing-original draft preparation, P.W.S., P.G. and J.K.; writing-review and editing, P.W.S., P.G. and J.K.; visualization, P.G.; supervision, P.W.S. All authors have read and agreed to the published version of the manuscript.

Funding: This research received no external funding. 
Acknowledgments: The work was carried out as part of the statutory activity of the Mineral and Energy Economy Research Institute, Polish Academy of Sciences.

Conflicts of Interest: The authors declare no conflict of interest.

\section{References}

1. Hussain, H.I.; Ślusarczyk, B.; Kamarudin, F.; Thaker, H.M.T.; Szczepańska-Woszczyna, K. An Investigation of an Adaptive Neuro-Fuzzy Inference System to Predict the Relationship among Energy Intensity, Globalization, and Financial Development in Major ASEAN Economies. Energies 2020, 13, 850. [CrossRef]

2. Kaszyński, P.; Kamiński, J. Coal Demand and Environmental Regulations: A Case Study of the Polish Power Sector. Energies 2020, 13, 1521. [CrossRef]

3. Kamiński, J.; Kudełko, M. The prospects for hard coal as a fuel for the Polish power sector. Energy Policy 2010, 38, 7939-7950. [CrossRef]

4. Szuba, J.; Michalik, L. Karbochemia-Zarys Rozwoju; Publishing House: Śląsk, Poland, 1983.

5. Borowiecki, T.; Kijeński, J.; Machnikowski, J.; Ściążko, M. (Eds.) Czysta Energia, Produkty Chemiczne i Paliwa z Węgla; Wydawnictwo Instytutu Chemicznej Przeróbki Węgla: Zabrze, Poland, 2008.

6. Chmielniak, T.; Ściążko, M. Technologie zgazowania węgla. Karbo 2007, 2, 93-97.

7. Hycnar, J.J. Kierunki rozwoju procesów zgazowania paliw. Karbo 2008, 1, 13-21.

8. Jasiński, A.W. Zgazowanie jako czysta technologia wykorzystania surowców zawierających węgiel. Karbo 2010, 2, 67-74.

9. Creedy, D.P.; Ganner, K.; Oakey, J.E. Clean Energy from Underground Coal Gasification in China; Technical Report; Department of Trade and Industry: London, UK, 2004.

10. Białecka, B. Podziemne Zgazowanie Węgla: Podstawy Procesu Decyzyjnego; Główny Instytut Górnictwa: Katowice, Poland, 2008; ISBN 9788361126133.

11. Copeland, T.E.; Antikarov, V. Real Options: A Practitioner's Guide; Texere: New York, NY, USA, 2001; ISBN 9781587991868.

12. Trigeorgis, L. Real Options: Managerial Flexibility and Strategy in Resource Allocation; MIT Press: Cambridge, MA, USA, 1996; ISBN 9780262201025.

13. Copeland, T.; Koller, T.; Murrin, J. Valuation: Measuring and Managing the Value of Companies, 3rd ed.; John Wiley \& Sons, Inc.: New York, NY, USA, 2000; ISBN 978-0471361909.

14. Herbelot, O. Option Valuation of Flexible Investments: The Case of a Coal Gasifier; MIT Center for Energy and Environmental Policy Research: Cambridge, MA, USA, 1994.

15. Smeers, Y.; Bolle, L.; Squilbin, O. Coal Options: Evaluation of Coal-Based Power Generation in an Uncertain Context; UCL Universite catholique de Louvain, CORE - Unité TERM: Brussel, Belgium, 2001.

16. Black, F.; Scholes, M. The Pricing of Options and Corporate Liabilities. J. Polit. Econ. 1973, 81, 637-654. [CrossRef]

17. Merton, R.C. Theory of rational option pricing. Theory Valuat. 2005, 4, 229-288.

18. Reedman, L.; Graham, P.; Coombes, P. Using a Real-Options Approach to Model Technology Adoption Under Carbon Price Uncertainty: An Application to the Australian Electricity Generation Sector*. Econ. Rec. 2006, 82, S64-S73. [CrossRef]

19. Yang, M.; Blyth, W. Modeling Investment Risks and Uncertainties with Real Options Approach; International Energy Agency Working Paper Series; A Working Paper for an IEA Book: Climate Policy Uncertainty and Investment Risk; International Energy Agency: Paris, France, 2007.

20. Kulatilaka, N. The value of flexibility: A general model of real options. In Real Options in Capital Investment; Trigeorgis, L., Ed.; Praeger: New York, NY, USA, 1995.

21. Kulatilaka, N.; Trigeorgis, L. The general flexibility to switch: Real options revisited. In Real Options Investment under Uncertain Classical Readings Recent Contributions; Schwartz, E.S., Trigeorgis, L., Eds.; MIT Press: Cambridge, MA, USA, 2004; pp. 179-196.

22. Gatfaoui, H. Pricing the (European) option to switch between two energy sources: An application to crude oil and natural gas. Energy Policy 2015, 87, 270-283. [CrossRef]

23. Sekar, R.C. Carbon Dioxide Capture from Coal-Fired Power Plants: A Real Options Analysis; MIT Technology and Policy Program; MIT LFEE 2005-002 RP; Cambridge, MA, USA, 2005; Available online: https://sequestration. mit.edu/pdf/LFEE_2005-002_RP.pdf (accessed on 28 March 2019). 
24. Yun, T.; Baker, R. Analysis of a power plant investment opportunity under a carbon neutral world. Invest. Manag. Financ. Innov. 2009, 6, 155-163.

25. Teng, Y.Y.; Han, L.P.; Li, C.Q. Real Option Analysis on Coal-to-oil Project. Energy Procedia 2011, 5, 48-52. [CrossRef]

26. Laurikka, H. Option value of gasification technology within an emissions trading scheme. Energy Policy 2006, 34, 3916-3928. [CrossRef]

27. Ammerlaan, A.L.M. Implementing Real Options in Engineering Projects: A Conceptual Framework to adopt Real Options. Master's Thesis, TU Delft, Faculty of Technology, Policy and Management, Delft, The Netherlands, 2010. Available online: https://repository.tudelft.nl/islandora/object/uuid\%3Ac5dd967b013a-4641-bbd3-021cf6e9d984 (accessed on 28 March 2019).

28. Abadie, L.M.; Chamorro, J.M. Valuing flexibility: The case of an Integrated Gasification Combined Cycle power plant. Energy Econ. 2008, 30, 1850-1881. [CrossRef]

29. De Oliveira, D.L.; Brandão, L.E.; Igrejas, R.; Gomes, L.L. Switching outputs in a bioenergy cogeneration project: A real options approach. Renew. Sustain. Energy Rev. 2014, 36, 74-82. [CrossRef]

30. Abadie, L.M. Operating flexibility at power plants: A market valuation. Int. J. Electr. Power Energy Syst. 2015, 64, 41-49. [CrossRef]

31. Kryzia, D.; Kopacz, M.; Kryzia, K. The Valuation of the Operational Flexibility of the Energy Investment Project Based on a Gas-Fired Power Plant. Energies 2020, 13, 1567. [CrossRef]

32. Kujanpää, L.; Pursiheimo, E. Techno-economic Evaluation of Flexible CCS Concepts in a CHP System. Energy Procedia 2017, 114, 6638-6649. [CrossRef]

33. Han, Y.; Shen, B.; Zhang, T. A Techno-economic Assessment of Fuel Switching Options of Addressing Environmental Challenges of Coal-Fired Industrial Boilers: An analytical work for China. Energy Procedia 2017, 142, 3083-3087. [CrossRef]

34. Ghoddusi, H. Blending under uncertainty: Real options analysis of ethanol plants and biofuels mandates. Energy Econ. 2017, 61, 110-120. [CrossRef]

35. Elias, R.; Wahab, M.; Fang, L. Retrofitting carbon capture and storage to natural gas-fired power plants: A real-options approach. J. Clean. Prod. 2018, 192, 722-734. [CrossRef]

36. Fan, J.-L.; Xu, M.; Yang, L.; Zhang, X. Benefit evaluation of investment in CCS retrofitting of coal-fired power plants and PV power plants in China based on real options. Renew. Sustain. Energy Rev. 2019, 115, 109350. [CrossRef]

37. Saługa, P.W.; Kamiński, J. Hard coal project valuation based on real options approach: Multiplicative vs. arithmetic stochastic process. Gospod. Surowcami Miner. 2016, 32, 25-40. [CrossRef]

38. Liu, X.; Ronn, E.I. Using the binomial model for the valuation of real options in computing optimal subsidies for Chinese renewable energy investments. Energy Econ. 2020, 87, 104692. [CrossRef]

39. Saługa, P. Managerial Flexibility in Mineral Project Valuation. In Elastyczność Decyzyjna w Procesach Wyceny Projektów Geologiczno-Górniczych; Publishing House: Kraków, Poland, 2011; p. 268. ISBN 9788360195246.

40. Guthrie, G.A. Real Options in Theory and Practice; Oxford University Press: Oxford, UK, 2009; ISBN 978-0195380637.

41. ARE. Sytuacja Techniczno-Ekonomiczna Sektora Elektroenergetycznego; Agencja Rynku Energii: Warszawa, Poland, 2019.

42. Methanex. Available online: www.methanex.com (accessed on 28 March 2019).

43. Statistics Poland. Available online: http://stat.gov.pl/ (accessed on 18 November 2019).

44. Cox, J.C.; Ross, S.A.; Rubinstein, M. Option pricing: A simplified approach. J. Financ. Econ. 1979, 7, $229-263$. [CrossRef]

45. Weber, C. Uncertainty in the Electric Power Industry: Methods and Models for Decision Support; Springer Science \& Business Media: New York, NY, USA, 2005.

46. Sterman, J.D. Business Dynamics: Systems Thinking and Modeling for a Complex World; McGraw-Hill Education: New York, NY, USA, 2000.

(C) 2020 by the authors. Licensee MDPI, Basel, Switzerland. This article is an open access article distributed under the terms and conditions of the Creative Commons Attribution (CC BY) license (http://creativecommons.org/licenses/by/4.0/). 